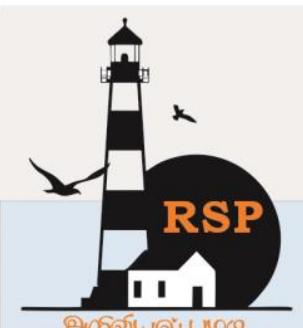

INTERNATIONAL RESEARCH JOURNAL ON ADVANCED SCIENCE HUB

\title{
Inhibition of Mineralization of Urinary Calcium Phosphate Stones by Sodium Pyrophosphate
}

\author{
Nilam Kumari ${ }^{1}$, Dr. Naresh Kumar ${ }^{2}$ \\ ${ }^{1}$ Research scholar, Department of Chemistry, B. N. Mandal University, Madhepura, Bihar-852113 \\ ${ }^{2}$ Professor, Department of Chemistry, B. N. Mandal University, Madhepura, Bihar-852113 \\ Inilam.nkd@gmail.com, ${ }^{2}$ drnareshchem@gmail.com
}

\begin{abstract}
To understand the biological importance of sodium pyrophosphate and its applicability as inhibitors in urolithiasis disease, we have studied the inhibition efficiency of sodium pyrophosphate towards the mineralization of urinary stone forming minerals like calcium phosphate, in aqueous as well as urinary medium. An attempt has been made to unfold, tentatively, the mechanism of inhibition by this inhibitor. It was Observational experiment. The Study was Conducted in the chemistry lab of university department of chemistry, B N Mandal University, Madhepura (Bihar) An experimental model was designed by taking the salt forming solutions, the whole operation took about 40-50 min. At the end the contents of beaker were digested in a hot water bath, cooled to room temperature and centrifuged in small volumes. The total centrifugate was collected and Calcium and carbonate content of the centrifugate of calcium carbonate mineralization experiments were determined. Sodium pyrophosphate has a moderate inhibition efficiency towards calcium carbonate mineralization. At $0.05 \mathrm{M}$ concentration, sodium pyrophosphate has a net inhibition of $30 \%$ which is $26.65 \%$ more than that of water (blank). Compared to water the percentage inhibition increased by $795.52 \%$. With decreasing concentrations of sodium pyrophosphate, the inhibition efficiency decreases. At very low concentration $(0.01 \mathrm{M})$ its inhibition is only slightly higher than that of water. In urinary medium sodium pyrophosphate seems to function as a better inhibitor of phosphate mineralization. At $0.05 \mathrm{M}$ concentration, sodium pyrophosphate has a net inhibition of $89.22 \%$ which is $75.36 \%$ more than that of urine. It is observed that sodium pyrophosphate solution, under different concentrations, exhibits moderate to good efficiency of inhibition towards mineralization of urinary stone forming minerals like calcium carbonate in aqueous as well as urinary medium.

Key words: Urolithiasis, sodium pyrophosphate, centrifuge, inhibition
\end{abstract}

\section{Introduction}

The urinary stone formation is related to the level of inhibitors of present in urine ${ }^{1}$. Human urine is known to contain some low as well as high molecular weight inhibitors like citrate, glycosaminoglycans, magnesium, zinc and sodium pyrophosphate. However, the mechanism of the action of these inhibitors are yet to be clearly established. The anions The urinary stone formation is related to the level of inhibitors of present in urine ${ }^{1}$. Human urine is known to contain some low as well as high molecular weight inhibitors like citrate, glycosaminoglycans, magnesium, zinc and sodium pyrophosphate. However, the mechanism of the action of these inhibitors are yet to be clearly established. The anions like citrate and pyrophosphate have been surmised to act by forming soluble-chelation of calcium ions. So far as the mechanism of action of inhibitor anions like pyrophosphate concerned, it is not yet well established. Effect of magnesium and 
zinc on urolithiasis risk factors have been studied ${ }^{2-}$ ${ }^{4}$. Attempts to correlate urinary levels to urolithiasis have been made ${ }^{3,4}$. However, pyrophosphate inhibitory capacities towards lithogenesis in the urinary tract have not yet been quantified and the corresponding chemical mechanisms have not been unraveled. A quest in this direction would be of applied value. Pyrophosphate is an inorganic compound with the formula $\mathrm{Na}_{4} \mathrm{P}_{2} \mathrm{O}_{7}$. It is a white, water-soluble salt. It is composed of pyrophosphate anion and sodium cations. It was first identified as a key endogenous inhibitor of biomineralization in the 1960s. The major source of pyrophosphate appears to be extracellular ATP, which is released from cells in a controlled manner. ${ }^{5,6}$. Our study would summarize the inhibition efficiency of pyrophosphate towards calcium sulphate stone in water as well as in urinary medium.[1-6]

\section{Methodology}

It was an observational experiment. The Study was Conducted in the chemistry lab of university department of chemistry, B N Mandal University, Madhepura. (Bihar) during a period between January 2019 and June 2019. An experimental model was designed with the two salt forming solutions and the inhibitor (pyrophosphate) falling simultaneously to a weaker from three separate burettes. Crystalloid forming solutions, viz., solutions of calcium acetate, potassium hydrogen phosphate, sodium pyrophosphate were prepared in distilled water. Four experimental models namely simultaneous Flow Static Model (S.S.M), Simultaneous Flow Dynamic Model (S.D.M), Reservoir Static Model (R.S.M), and Reservoir Dynamic Model (R.D.M), were designed. In the S.S.M model the two salts forming solution, e.g. potassium hydrogen Phosphate and Calcium Acetate (for calcium phosphate) and the inhibitor (sodium pyrophosphate) were taken in three separate burettes $(50 \mathrm{ml})$ and were allowed to fall simultaneously into a $250 \mathrm{ml}$ beaker in a slow (dropwise) and equal speed.

The whole operation took about $50 \mathrm{~min}$ to 1 hour. At the end of the experiment, the contents of beaker were digested in a hot water bath for $10 \mathrm{~min}$, cooled to room temperature and centrifuged in small volumes. The total centrifugate was collected. Next, the precipitates of the centrifugate in case of calcium phosphate mineralization experiments were determined. Simultaneous blank experiments with water/urine in place of inhibitor solution were also carried out for evaluating the inhibition efficiency of inhibitors compared to water/urine. All experiments were conducted at room temperature $\left(20-25^{\circ} \mathrm{C}\right) . \mathrm{pH}$ value is maintained at 6.5.[7-12]

\section{Estimations and calculations}

Calcium was estimated by complexometric method using standard disodium EDTA solution? phosphate was estimated by ammonium molybdate solution $\left[\left(\mathrm{NH}_{4}\right)_{6} \mathrm{Mo}_{7} \mathrm{O}_{6} .4 \mathrm{H}_{2} \mathrm{O}\right]$. While calculating the calcium contents of centrifugate, an EDTA titer value, equivalent to the total inhibitor solution (pyrophosphate solution) was deducted from the total titer value (equivalent to the centrifugate). This was done because pyrophosphate that is present in the centrifugate, would also consume some EDTA. While calculating the phosphate content of the centrifugate in case of experiments with inhibitor solution in urinary media, a molybdate titer value equivalent to $50 \mathrm{~mL}$ urine was deducted from the total titer value (equivalent to the centrifugate). This was done because urine itself would consume some molybdate due to its own phosphate and probably other reducing substances. Inhibition efficiency of the inhibitor solutions (including that of water/urine) was calculated using the formula Inhibition efficiency

$(\%$ inhibition $)=\frac{\mathrm{Ca}^{++} \text {or phosphate in centrifugate }}{\text { Total } \mathrm{Ca}^{++} \text {or phosphate in experiment }}$

\section{Results \& discussions}

A study of Table-1 suggests that sodium pyrophosphate has a moderate to good inhibition efficiency towards calcium phosphate mineralization. At $0.05 \mathrm{M}$ concentration, $\mathrm{Na}_{4} \mathrm{P}_{2} \mathrm{O}_{7}$ has a net inhibition of $55.35 \%$ which is $46.43 \%$ more than that of water (blank). Compared to water the percentage inhibition increased by $520.51 \%$. With decreasing concentrations of the inhibitor, it is observed that the inhibition efficiency decreases. At very low concentration $(0.01 \mathrm{M})$ the inhibition of pyrophosphate is found to be only slightly higher than that of water that is $11.70 \%$ more. In urinary medium (Table-2) $\mathrm{Na}_{4} \mathrm{P}_{2} \mathrm{O}_{7}$ seems to function as a better inhibitor of phosphate mineralization although urine itself is an inhibitor. In blank the inhibition capacity of urine(blank) is found to be $11.16 \%$. This inhibition efficiency of pure urine 
www.rspsciencehub.com

might be due to its natural inhibitors like citrate, $\mathrm{Mg}^{++}$, pyrophosphate etc.

At $0.05 \mathrm{M}$ concentration the net inhibition of pyrophosphate is as high as $54.12 \%$, which comes to $42.96 \%$ higher than that of urine. With decreasing concentration of $\mathrm{Na}_{4} \mathrm{P}_{2} \mathrm{O}_{7}$, the inhibition has been found to gradually decrease and becomes only slightly higher than that of pure urine at 0.01 $\mathrm{M}$ strength. Thus, only up to $0.005 \mathrm{M}$ strength pyrophosphate can be a good inhibitor. Calcium phosphate is the most frequently occurring constituent of urinary calculi after calcium oxalate which is the most abundant ${ }^{9}$. It is the most stubborn constituent. A moderate inhibition of phosphate by $\mathrm{Na}_{4} \mathrm{P}_{2} \mathrm{O}_{7}$ up to as low as $0.05 \mathrm{M}$ concentration, particularly in urinary medium, suggests that pyrophosphate ion would be a useful inhibitor of stone formation in the urinary tract.

Sodium pyrophosphate binds with phosphate ions and, in turn, screens the (Phosphate) from $\mathrm{Ca}^{++}$, thus, calcium phosphate precipitation is inhibited.

Table:1. Inhibition of mineralization of calcium oxalate by pyrophosphate ions in aqueous medium

\begin{tabular}{|c|c|c|c|c|c|c|}
\hline Inhibitor & $\begin{array}{l}\text { Strength } \\
\text { of } \\
\text { inhibitor } \\
\text { solution } \\
\text { (M) }\end{array}$ & $\begin{array}{c}\text { phosphate } \\
\text { in solution } \\
(\mathrm{mg})\end{array}$ & $\begin{array}{l}\text { Phosphate } \\
\text { precipitated } \\
\text { (mg) }\end{array}$ & Inhibition & $\begin{array}{l}\text { Increase of } \\
\text { Inhibition } \\
\text { over blank }\end{array}$ & $\begin{array}{c}\text { Increase of } \\
\text { Inhibition } \\
\text { relative to } \\
\text { blank }(\%)\end{array}$ \\
\hline $\begin{array}{l}\text { Water } \\
\text { (Blank) }\end{array}$ & - & 5.00 & 51.00 & 8.92 & - & - \\
\hline $\mathrm{Na}_{4} \mathrm{P}_{2} \mathrm{O}_{7}$ & 0.010 & 11.55 & 44.45 & 20.62 & 11.70 & 131.16 \\
\hline $\mathrm{Na}_{4} \mathrm{P}_{2} \mathrm{O}_{7}$ & 0.015 & 13.68 & 42.32 & 24.42 & 15.50 & 173.76 \\
\hline $\mathrm{Na}_{4} \mathrm{P}_{2} \mathrm{O}_{7}$ & 0.020 & 17.04 & 38.96 & 30.42 & 21.50 & 241.03 \\
\hline $\mathrm{Na}_{4} \mathrm{P}_{2} \mathrm{O}_{7}$ & 0.025 & 17.78 & 38.22 & 31.75 & 22.83 & 255.94 \\
\hline $\mathrm{Na}_{4} \mathrm{P}_{2} \mathrm{O}_{7}$ & 0.030 & 20.15 & 35.85 & 35.98 & 27.06 & 303.36 \\
\hline $\mathrm{Na}_{4} \mathrm{P}_{2} \mathrm{O}_{7}$ & 0.035 & 23.72 & 32.28 & 42.35 & 33.43 & 374.77 \\
\hline $\mathrm{Na}_{4} \mathrm{P}_{2} \mathrm{O}_{7}$ & 0.040 & 24.65 & 31.35 & 44.01 & 35.09 & 393.38 \\
\hline $\mathrm{Na}_{4} \mathrm{P}_{2} \mathrm{O}_{7}$ & 0.045 & 27.20 & 28.80 & 48.57 & 39.65 & 444.50 \\
\hline $\mathrm{Na}_{4} \mathrm{P}_{2} \mathrm{O}_{7}$ & 0.050 & 31.00 & 25.00 & 55.35 & 46.43 & 520.51 \\
\hline
\end{tabular}


Table: 2. Inhibition of mineralization of calcium oxalate by pyrophosphate ions in urinary medium

\begin{tabular}{|c|c|c|c|c|c|c|}
\hline Inhibitor & $\begin{array}{l}\text { Strength of } \\
\text { inhibitor } \\
\text { solution } \\
\text { (M) }\end{array}$ & $\begin{array}{l}\text { Phosphate } \\
\text { in solution } \\
\quad(\mathrm{mg})\end{array}$ & $\begin{array}{l}\text { Phosphate } \\
\text { precipitated } \\
\text { (mg) }\end{array}$ & Inhibition & $\begin{array}{l}\text { Increase of } \\
\text { Inhibition } \\
\text { over blank }\end{array}$ & $\begin{array}{c}\text { Increase of } \\
\text { Inhibition } \\
\text { relative to } \\
\text { blank }(\%)\end{array}$ \\
\hline $\begin{array}{l}\text { Urine } \\
\text { (Blank) }\end{array}$ & - & 5.58 & 44.42 & 11.16 & - & - \\
\hline $\mathrm{Na}_{4} \mathrm{P}_{2} \mathrm{O}_{7}$ & 0.010 & 6.10 & 43.90 & 12.20 & 1.04 & 9.32 \\
\hline $\mathrm{Na}_{4} \mathrm{P}_{2} \mathrm{O}_{7}$ & 0.015 & 6.72 & 43.28 & 13.44 & 2.28 & 20.43 \\
\hline $\mathrm{Na}_{4} \mathrm{P}_{2} \mathrm{O}_{7}$ & 0.020 & 8.44 & 41.56 & 16.88 & 5.72 & 51.50 \\
\hline $\mathrm{Na}_{4} \mathrm{P}_{2} \mathrm{O}_{7}$ & 0.025 & 11.1 & 38.90 & 22.20 & 11.04 & 98.92 \\
\hline $\mathrm{Na}_{4} \mathrm{P}_{2} \mathrm{O}_{7}$ & 0.030 & 14.64 & 35.36 & 29.28 & 18.12 & 162.36 \\
\hline $\mathrm{Na}_{4} \mathrm{P}_{2} \mathrm{O}_{7}$ & 0.035 & 17.96 & 32.04 & 35.92 & 24.76 & 221.86 \\
\hline $\mathrm{Na}_{4} \mathrm{P}_{2} \mathrm{O}_{7}$ & 0.040 & 20.53 & 29.47 & 41.06 & 29.90 & 267.92 \\
\hline $\mathrm{Na}_{4} \mathrm{P}_{2} \mathrm{O}_{7}$ & 0.045 & 23.16 & 26.84 & 46.32 & 35.68 & 319.71 \\
\hline & 0.050 & 27.06 & 22.04 & 54.12 & 42.96 & 384.95 \\
\hline
\end{tabular}

The phosphate ion $\left(\mathrm{PO}_{4}^{---}\right)$has a tetrahedral $\left(\mathrm{T}_{\mathrm{d}}\right)$ symmetry and shows 4 infrared absorption modes $^{10}$. These are symmetric P-O stretching $\left(\mathrm{v}_{1}\right)$ asymmetric $\mathrm{P}-\mathrm{O}$ stretching $\left(\mathrm{v}_{3}\right)$ and the two O-P-O bending modes ( $\mathrm{v}_{2}$ and $\left.\mathrm{v}_{4}\right)$. In a non-equivalent force field around the phosphate ion, however, there occurs distortion from the tetrahedral symmetry ${ }^{10,11}$. In case of ionic phosphate, the totally symmetric stretching mode $\left(\mathrm{v}_{1}\right)$ is Raman active, but in coordinated phosphates this band becomes IR active ${ }^{12}$. Presently the infrared spectra of the crystals, obtained from the centrifugate of reaction mixture of calcium chloride, sodium phosphate and pyrophosphate, showed a band of medium intensity at $1094 \mathrm{~cm}^{-1}$. This band may be assigned to asymmetric P-O stretch $\left(\mathrm{v}_{3}\right)$. The symmetric P-O stretch $\left(\mathrm{v}_{1}\right)$ showed rather low at $915 \mathrm{~cm}^{-1}$. Weak bands at 680 and 604 may be assigned to the two split components of O-P-O bending mode $\left(\mathrm{v}_{4}\right)$. Relatively low position of $\mathrm{v}_{3}$ band coupled with split of $\mathrm{v}_{4}$ band suggests a coordinated nature of phosphate in the crystals ${ }^{12}$.In the infrared spectra of the crystals from the centrifugate of calcium chloride, and sodium 


\section{www.rspsciencehub.com}

phosphate, the $\mathrm{v}_{3}$ band showed at $1155 \mathrm{~cm}^{-1}$ as a double headed peak. The $\mathrm{v}_{1}$ band has been observed just as a shoulder at $C a .950 \mathrm{~cm}^{-1}$. The $\mathrm{v}_{4}$ band, however, has been found to split into two, showing at 671 and $602 \mathrm{~cm}^{-1}$. Split of $v_{3}$ and $v_{4}$ bands suggests that the phosphate in the crystals is not ionic but is rather in some coordinated state. Thus, it seems, pyrophosphate inhibits calcium phosphate mineralization through sequestering-complexation of phosphate.

\section{Conclusion}

It is observed that sodium pyrophosphate, under different concentrations, exhibit moderate to good efficiency of inhibition towards mineralization of urinary stone forming minerals viz., calcium phosphate in aqueous as well as urinary milieu. Infrared studies suggested that the pyrophosphate ions inhibit calcium phosphate mineralization by sequestering complexation (soluble chelation) of phosphate. Inhibition of calcium phosphate by $\mathrm{Na}_{4} \mathrm{P}_{2} \mathrm{O}_{7}$, particularly in urinary medium, would be of applied value in the prevention and control of urolithiasis. All of our observations in the present study are in-vitro and from chemical point of view. In vivo studies in animal systems and also human trials can only prove the affectivity of the pyrophosphate in inhibition and dissolution of urinary stones. Our present in-vitro studies, nevertheless, would definitely form foundation for designing drugs for chemo-dissolution of urinary calculi.

\section{Acknowledgement}

I wish to thank the local practitioners for helping me during my work. I also like to thank my mentor and guide Dr. Naresh Kumar Sir and all professors for allowing me to conduct the experiments in lab of BNM university department of chemistry and also helping me during my lab work.

\section{References}

[1]. Joseph K C, Bharat, Parekh, B and Joshi M J, 'Inhibition of growth of urinary type calcium hydrogen phosphate dihydrate crystals by tartaric acid and tamarind', Current Science, 88 (25),1232, 2005.

[2]. Schulsinger DA (2014). Kidney Stone Disease: Say NO to Stones!. Springer. p. 27. Archived from the original on 8 September 2017.
[3]. Preminger: Stones in the Urinary Tract". In Cutler RE (ed.). The Merck Manual of Medical Information Home Edition (3rd ed.). Whitehouse Station, New Jersey: Merck Sharp and Dohme Corporation GM "Chapter 148, 2007

[4]. Nephrolithiasis Overview at eMedicine $\S$ Background.

[5]. Kalpana Devi V, Baskar R,Varalakshmi P. Biochemical effects in normal and stone forming rats treated with the ripe kernel juice of Plantain (Musa Paradisiaca). Ancient Science of Life, 3 \& 4, 1993, 451 - 461.

[6]. Coward RJ, Peters CJ, Duffy PG, Corry D, Kellett MJ, Choong S, van't Hoff WG. Epidemiology of paediatric renal stone disease in the UK. Arch Dis Child. 2003;88:962-

[7]. Campbell's Urology; (Ed.), Wash, Retik, Vaughon, Wein W.B, Saunders Company, Vol.3, 26611996.

[8]. Mahtab S. Bamji, Pralhad Rao.N, Vinodini Reddy, Text book of Human Nutrition, Oxford and IBH. Co. Pvt. Ltd., 3851996.

[9]. D.L. Perry S.L. Phillips, Handbook of inorganic compounds CRC Press ISBN 08493-8671-3, 1995

[10]. Klaus Schrödter; Gerhard Bettermann; Thomas Staffel; Friedrich Wahl; Thomas Klein; Thomas Hofmann. "Phosphoric Acid and Phosphates". Ullmann's Encyclopaedia of Industrial Chemistry. Weinheim: WileyVCH. doi:10.1002/14356007.a19_465.pub3..

[11]. Reilly RF, Ch. 13: "Nephrolithiasis". In Reilly Jr \& Perazella 2005, pp. 192-207.

[12]. National Kidney and Urologic Diseases Information Clearing house (2008). "Medullary Sponge Kidney (NIH Publication No. 08-6235)". Kidney \& Urologic Diseases: National Institute of Diabetes and Digestive and Kidney Diseases, National Institutes of Health, Public Health Service, from the original on 7 August 2011. Retrieved 27 July 2011. 